\title{
Rare Earth Oxide-containing Fluorescent Glass Filler for Composite Resin
}

\author{
Motohiro UO ${ }^{1}$, Mayumi OKAMOTO ${ }^{2}$, Fumio WATARI ${ }^{1}$, Kazutoshi TANI ${ }^{3}$, Manabu MORITA ${ }^{3}$ \\ and Akira SHINTANI ${ }^{4}$ \\ ${ }^{1}$ Division of Biomedical, Dental Materials and Engineering, Department of Oral Health Science, Graduate School of Dental \\ Medicine, Hokkaido University, North 13 West 7, Kita-ku, Sapporo 060, Japan \\ ${ }^{2}$ Division of Oral Functional Prosthodontics, Department of Oral Functional Science, Graduate School of Dental Medicine, \\ Hokkaido University, North 13 West 7, Kita-ku, Sapporo 060, Japan \\ ${ }^{3}$ Division of Preventive Dentistry, Department of Oral Health Science, Graduate School of Dental Medicine, Hokkaido Univer- \\ sity, North 13 West 7, Kita-ku, Sapporo 060, Japan \\ ${ }^{4}$ OptoElectronics Department, Toyoda Gosei Co. Ltd. (Present address: Koha Co. Ltd.) \\ Corresponding author, E-mail:uo@den.hokudai.ac.jp
}

Received December 13, 2004/Accepted January 14, 2005

\begin{abstract}
In recent dental care, esthetic restorative materials such as composite resin and porcelain have been widely used and studied. However, their good esthetics makes the visual inspection of restored teeth difficult. In this study, a fluorescent glass filler containing rare earth oxides - which are well-known fluorescent materials - was prepared and used in composite resin to enhance visual inspection capability with small change in color. For example, when irradiated with near ultraviolet light, an $\mathrm{Eu}_{2} \mathrm{O}_{3}$-containing filler fluoresced clearly and visibly. The fluorescence intensity of the prepared composite resin increased with increase of $\mathrm{Eu}_{2} \mathrm{O}_{3}$ content in the glass filler and with filler/resin ratio in the resin. Despite the clear fluorescence, the effect of $\mathrm{Eu}_{2} \mathrm{O}_{3}$ on the color change of composite resin was quite small - even when up to 10 wt $\% \mathrm{Eu}_{2} \mathrm{O}_{3}$ was added to the glass filler. $\mathrm{Tb}_{4} \mathrm{O}_{7^{-}}$and $\mathrm{Dy}_{2} \mathrm{O}_{3}$-added fillers also showed clear fluorescence, just like $\mathrm{Eu}_{2} \mathrm{O}_{3}$-added filler. Therefore, fluorescent glass fillers for composite resins, resulting in small color change in the latter, were successfully prepared in this study.
\end{abstract}

Key words: Rare earth oxide, Europium, Fluorescence, Filler, Composite resin

\section{INTRODUCTION}

In recent dental care, esthetics is of paramount importance to patients. Therefore, restorative materials such as composite resin and porcelain have been widely used and studied ${ }^{1-8)}$. However, because of their good esthetics, the visual inspection of restored teeth becomes difficult. In particular, quick and accurate inspection in mass dental health examinations becomes increasingly difficult for dentists. This is because detection is usually done by exploring the tactile difference on the tooth surface. If the composite resin shows some distinct optical feature, then visual inspection of the restored part could be easily achieved. Fluorescence is a good property for use as a non-contact detection method for various materials. As such, it has already been applied in many fields ${ }^{9-11)}$. In the current study, the authors applied the fluorescence detection method to discriminate between esthetic restoratives and teeth ${ }^{12,13)}$.

Rare earth oxides are well-known and widelyused fluorescent materials ${ }^{14)}$. Silicate glass, which constitutes the glass filler of composite resin, provides good solubility for other oxides containing rare earth oxides. Leveraging on this solubility property, a rare earth oxide-containing glass filler could then fluoresce - making visual inspection possible.

The purpose of this study was to prepare a fluorescent glass filler for use in a composite resin to enhance visual inspection capability without change in color.

\section{MATERIALS AND METHODS}

Preparation of fluorescent glass filler

Glass was prepared by mixing reagent grade chemicals $\mathrm{Na}_{2} \mathrm{~B}_{4} \mathrm{O}_{7}, \mathrm{~B}_{2} \mathrm{O}_{3}, \mathrm{Al}_{2} \mathrm{O}_{3}$, and $\mathrm{SiO}_{2}$ to form $10 \mathrm{Na}_{2} \mathrm{O}$. $49 \mathrm{~B}_{2} \mathrm{O}_{3} \cdot 1 \mathrm{Al}_{2} \mathrm{O}_{3} \cdot 40 \mathrm{SiO}_{2}$ (wt\%). Rare earth oxides $\left(\mathrm{Eu}_{2} \mathrm{O}_{3}, \mathrm{Dy}_{2} \mathrm{O}_{3}, \mathrm{~Tb}_{4} \mathrm{O}_{7}, \mathrm{Nd}_{2} \mathrm{O}_{3}, \mathrm{Ho}_{2} \mathrm{O}_{3}, \mathrm{Er}_{2} \mathrm{O}_{3}\right.$, and $\left.\mathrm{Sm}_{2} \mathrm{O}_{3}\right)$ were added to the above mixture at $2,5,7$, and 10 wt\%. The mixture was melted at $1100^{\circ} \mathrm{C}$ for two hours in air using an alumina crucible. The melt was cast in a brass mold into a thin sheet, and quenched. The prepared glass was crushed and sieved to be under $53 \mu \mathrm{m}$, and supplied for composite resin preparation.

\section{Preparation of composite resin}

Urethanedimethacrylate (UDMA; Shin Nakamura Kagaku, Wakayama, Japan) was used as the resin matrix. Camphoroquinone (Tokyo Kasei, Tokyo, Japan) was added to UDMA at $0.3 \mathrm{wt} \%$ as a photocure catalyst. The prepared glass filler and UDMA were mixed at filler/resin weight ratios $(f / r)$ of $1 / 1$, $2 / 1$, and $3 / 1$. The mixture was put in a plastic mold (8-mm diameter $\times 2$-mm thickness) and cured with a light curing unit (JetLight 3000, Morita, Tokyo, Japan) for 30 seconds from both sides. The cured 
specimen was applied for optical measurement without polish.

\section{Measurement of optical properties}

One human third molar was sliced perpendicular to the tooth axis to expose the enamel, and then polished with $\phi 2 \mu \mathrm{m}$ alumina slurry to expose the dentin. Their fluorescence spectra were measured using a fluorescence spectrophotometer (F-2500, Hitachi, Tokyo, Japan) under the following conditions: slit width $=2.5 \mathrm{~nm}$, wavelength scanning speed $=300$ $\mathrm{nm} / \mathrm{min}$. When irradiated by a purple light-emitting diode (purple-LED ${ }^{\circledR}$; Toyoda Gosei Co. Ltd., Nakajima-gun, Aichi, Japan), the fluorescence image was observed and recorded with a digital camera (D60, Canon Co. Ltd., Tokyo, Japan). The camera was attached with a sharp cut filter (O56, Hoya Co. Ltd., Tokyo, Japan) to cut off irradiating light. The effect of $\mathrm{Eu}_{2} \mathrm{O}_{3}$ content - in the filler - on the color of composite resin was estimated with a colordifference meter (OFC-300A, Nihon Denshoku Kogyo Co. Ltd., Tokyo, Japan). For each condition, the fluorescent measurement and color estimation were carried out once for each specimen.

\section{RESULTS}

The excitation and emission spectra of $10 \mathrm{wt} \% \mathrm{Eu}_{2} \mathrm{O}_{3}$ containing filler mixed at $\mathrm{f} / \mathrm{r}=3 / 1$ are shown in Fig. 1. Sharp peaks were observed in both the excitation and emission spectra. Strong excitation bands were distributed in the wavelengths below $400 \mathrm{~nm}$ and strong peaks were observed at $395 \mathrm{~nm}$ and $382 \mathrm{~nm}$. As for the emission spectrum, strong peak was observed at around $613 \mathrm{~nm}$.

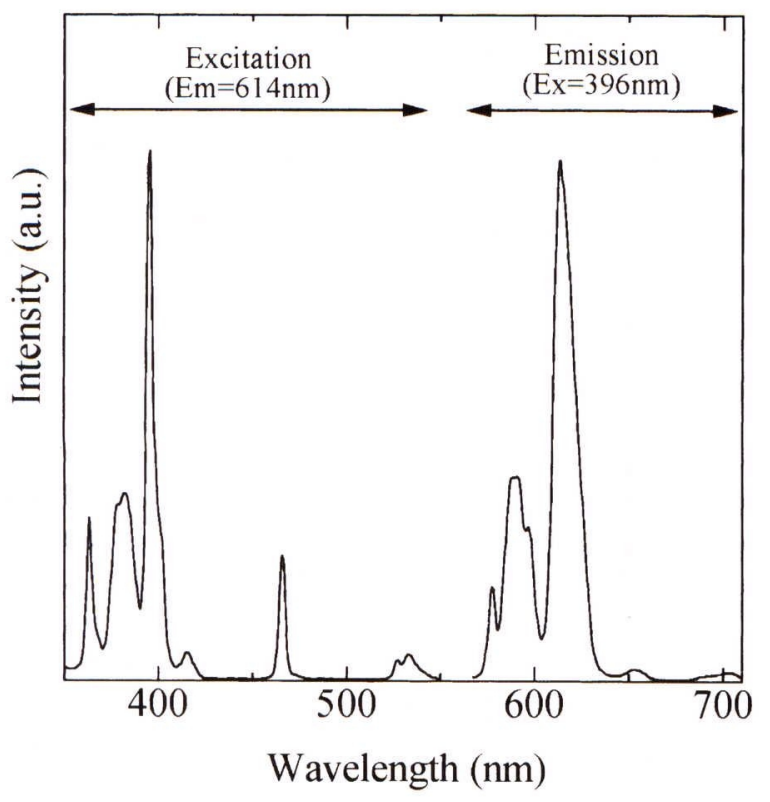

Fig. 1 The excitation and emission spectra of $10 \mathrm{wt} \%$ $\mathrm{Eu}_{2} \mathrm{O}_{3}$-containing filler mixed at $\mathrm{f} / \mathrm{r}=3 / 1$.
As shown in Fig. 2, the fluorescence intensity at $613 \mathrm{~nm}$ when excited at $396 \mathrm{~nm}$ was dependent on two factors: $\mathrm{Eu}_{2} \mathrm{O}_{3}$ content in the glass filler and filler/resin ratio $(\mathrm{f} / \mathrm{r})$. Fluorescence intensity increased with increase in both the $\mathrm{Eu}_{2} \mathrm{O}_{3}$ content and filler/resin ratio. Each intensity curve was saturated with increase in $\mathrm{Eu}_{2} \mathrm{O}_{3}$ content in the glass filler. This was caused by self-absorption or concentration quenching of fluorescence. At 5 wt $\% \quad \mathrm{Eu}_{2} \mathrm{O}_{3}$ filler and $\mathrm{f} / \mathrm{r}=2 / 1$, more than $50 \%$ of maximum emission (i.e., 10 wt $\% \mathrm{Eu}_{2} \mathrm{O}_{3}$ filler and $\mathrm{f} / \mathrm{r}=3 / 1$ ) was already achieved.

The fluorescence image of $\mathrm{Eu}_{2} \mathrm{O}_{3}$-containing composite under purple-LED $(383 \mathrm{~nm})$ irradiation is shown in Fig. 3. For comparison purpose, a conventional commercial composite (Vita Shade, 3M) was also shown in the figure. A clear fluorescence visibly emitted from the $\mathrm{Eu}_{2} \mathrm{O}_{3}$-containing composite, where the composite could be easily identified by the fluorescence through macroscopic observation. By contrast, the commercial composite did not show clear fluorescence under the same irradiation conditions.

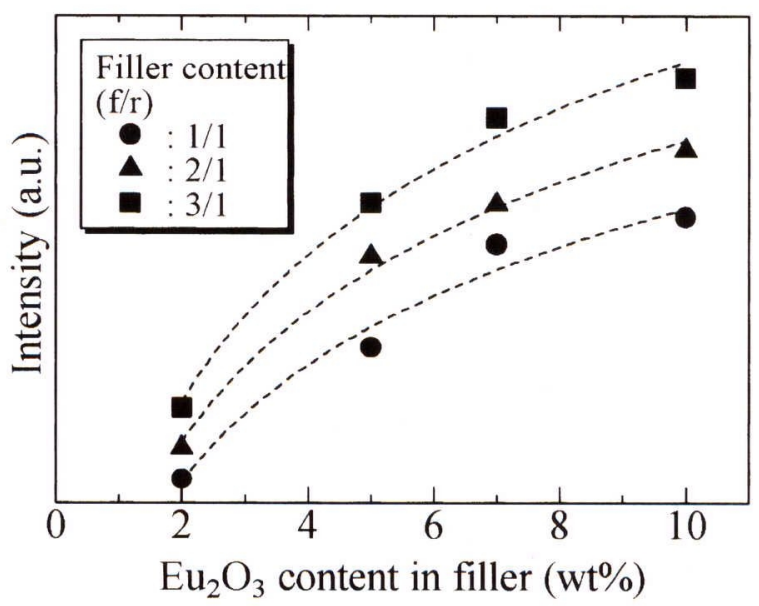

Fig. 2 The dependency of fluorescence intensity (at $613 \mathrm{~nm}$ under excitation at $396 \mathrm{~nm}$ ) on filler/ resin ratio $(\mathrm{f} / \mathrm{r})$ and $\mathrm{Eu}_{2} \mathrm{O}_{3}$ content in glass filler.

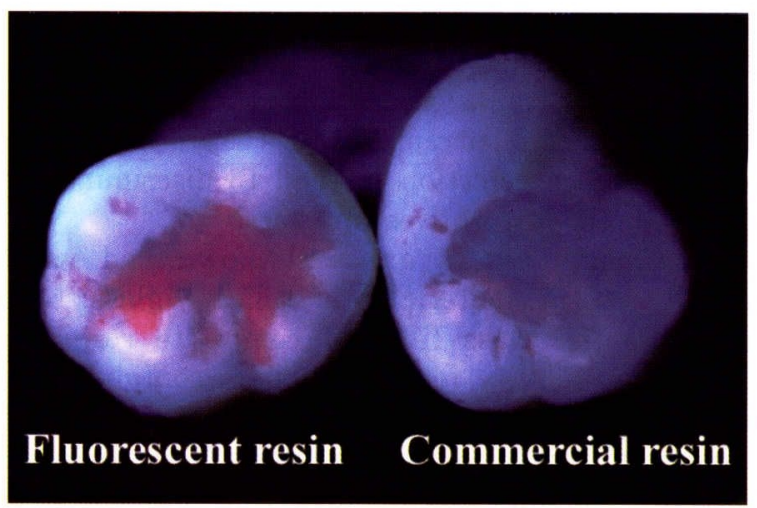

Fig. 3 The fluorescence image of $\mathrm{Eu}_{2} \mathrm{O}_{3}$-containing composite under purple LED $(383 \mathrm{~nm})$ irradiation. 
The effect of $\mathrm{Eu}_{2} \mathrm{O}_{3}$ addition - to the filler - on the color change of composites is shown in Table 1. At $\mathrm{f} / \mathrm{r}=2 / 1$, Table 1 shows the $\mathrm{L}^{*}, \mathrm{a}^{*}$, and $\mathrm{b}^{*}$ parameters of the CIE color system for composites with $\mathrm{Eu}_{2} \mathrm{O}_{3}$-containing fillers and filler without $\mathrm{Eu}_{2} \mathrm{O}_{3}$. The effect of $\mathrm{Eu}_{2} \mathrm{O}_{3}$ content on color change was very small, such that any difference in color among the composites was not distinctly visible to the eye. Therefore, the effect of $\mathrm{Eu}_{2} \mathrm{O}_{3}$ on the color change of composite resin was negligible.

Fig. 4 shows the emission spectra of $\mathrm{Eu}_{2} \mathrm{O}_{3}$ containing composite, enamel, and dentin under exci-

Table 1 The effect of $\mathrm{Eu}_{2} \mathrm{O}_{3}$ content on color of composites (at $\mathrm{f} / \mathrm{r}=2 / 1$ )

\begin{tabular}{cccc}
\hline Eu content $(\%)$ & $\mathrm{L}^{*}$ & $\mathrm{a}^{*}$ & $\mathrm{~b}^{*}$ \\
\hline 0 & 50.6 & -1.0 & 1.0 \\
5 & 49.6 & -0.7 & 1.4 \\
10 & 52.3 & -1.0 & 2.2 \\
\hline
\end{tabular}

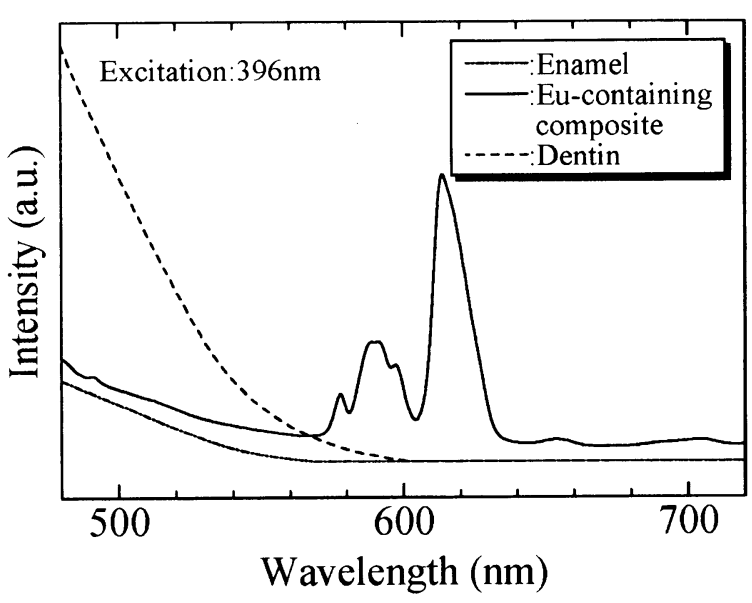

Fig. 4 The emission spectra of $\mathrm{Eu}_{2} \mathrm{O}_{3}$-containing composite, enamel, and dentin under excitation at $396 \mathrm{~nm}$.

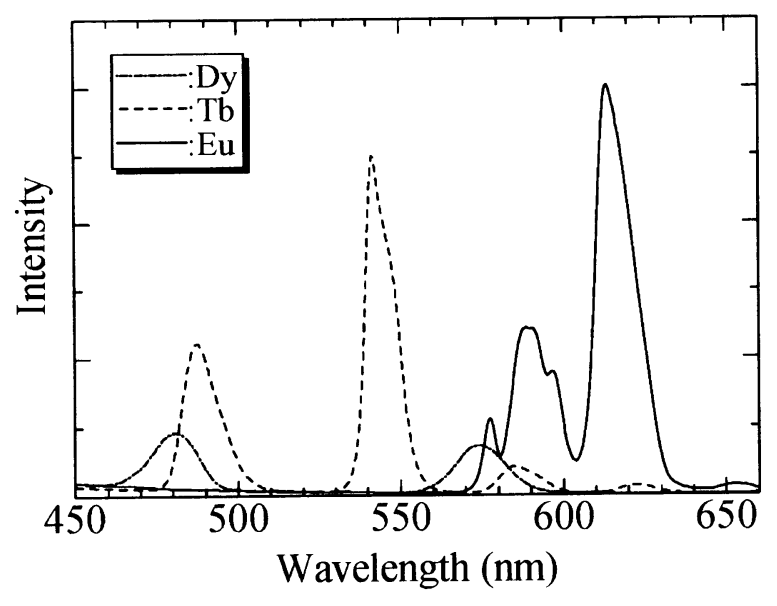

Fig. 5 The emission spectra of the composites with $\mathrm{Tb}_{4} \mathrm{O}_{7^{-}}$and $\mathrm{Dy}_{2} \mathrm{O}_{3}$-containing fillers (10 wt\%).

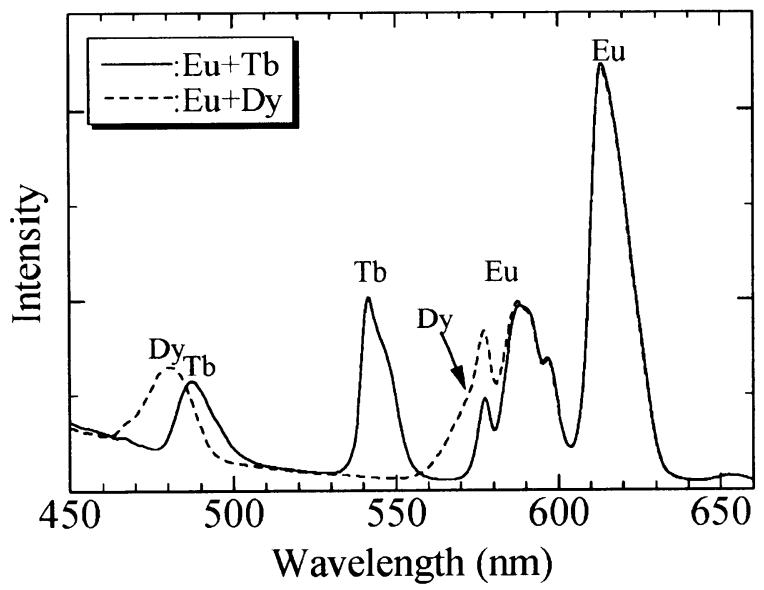

Fig. 6 The emission spectra of the composites with $\mathrm{Eu}_{2} \mathrm{O}_{3} / \mathrm{Tb}_{4} \mathrm{O}_{7}$ or $\mathrm{Eu}_{2} \mathrm{O}_{3} / \mathrm{Dy}_{2} \mathrm{O}_{3}$.

tation at $396 \mathrm{~nm}$. The $\mathrm{Eu}_{2} \mathrm{O}_{3}$-containing composite showed higher emission intensity than enamel within the observed wavelength range. Dentin had higher emission intensity at wavelengths shorter than 560 $\mathrm{nm}$, while $\mathrm{Eu}_{2} \mathrm{O}_{3}$-containing composite showed higher emission intensity at wavelengths longer than 560 $\mathrm{nm}$. By using an appropriate filter to pass wavelengths longer than $560 \mathrm{~nm}$, the emission of $\mathrm{Eu}_{2} \mathrm{O}_{3}$-containing composite could be clearly differentiated from dentin.

Fig. 5 shows the emission spectra of the composites containing fillers with $\mathrm{Tb}_{4} \mathrm{O}_{7}$ and $\mathrm{Dy}_{2} \mathrm{O}_{3}(10$ wt\%). Both $\mathrm{Tb}_{4} \mathrm{O}_{7}$ and $\mathrm{Dy}_{2} \mathrm{O}_{3}$ showed clear emissions, but not so for composites that contained other rare earth oxides. Fig. 6 shows the emission spectra of composites with both $\mathrm{Eu}_{2} \mathrm{O}_{3}$ and $\mathrm{Tb}_{4} \mathrm{O}_{7}$ or $\mathrm{Dy}_{2} \mathrm{O}_{3}$ (5 wt\% respectively). The emissions from $\mathrm{Eu}, \mathrm{Tb}$, and Dy were easily identified and assigned.

\section{DISCUSSION}

Due to the recent improvement of esthetic restorative materials such as composite resin and porcelain, greater skills are now required of dentists to detect resin-filled teeth. As shown in Fig. 3, an $\mathrm{Eu}_{2} \mathrm{O}_{3}$ containing glass filler lent a strong fluorescent property to the composite resin when the latter was irradiated by purple or near ultraviolet light. The fluorescence could be observed visually. Further, as shown in Table 1, the addition of $\mathrm{Eu}_{2} \mathrm{O}_{3}$ did not affect the color of composite resin. This meant that the effect of $\mathrm{Eu}_{2} \mathrm{O}_{3}$ content on the color change of composite resin was negligibly small.

As for the light source, a purple or near ultraviolet LED was used. Compared to conventional light sources, these LED light sources wielded several advantages: small in size, sharp emission spectrum, and low electricity consumption. And these advantages were the reasons that made LED an appropri- 
ate inspection device in the oral cavity.

The authors have studied the discrimination of esthetic restorative materials based on their fluorescent properties ${ }^{12,13)}$. Most commercial porcelains and composite resins show typical fluorescence at the longer wavelengths when irradiated by blue light. Therefore, the possibility of non-contact discrimination of these materials was suggested. To confirm this possibility, the present study designed an easy and clear method to discriminate between composite resin and tooth using rare earth oxides - which could likewise be applied to porcelains.

As shown in Figs. 5 and 6, $\mathrm{Tb}_{4} \mathrm{O}_{7}$ - and $\mathrm{Dy}_{2} \mathrm{O}_{3}$ containing composite resins also showed clear fluorescence, just like $\mathrm{Eu}_{2} \mathrm{O}_{3}$, and their emissions also easily assigned. This indicated the possibility of systematic recording of data when the combination and/or composition of these rare earth oxide-containing glass fillers were changed. For example, in the current study, the presence (or absence) of the three rare earth oxides could be expressed as three bits of data. If a glass filler contained $\mathrm{Er}$ and $\mathrm{Tb}$ but without Dy, the expression could be assigned as $(1,1,0)$. By including the composition of rare earth oxide in the filler as a parameter, more information could be expressed. Thus, with this method, it would be possible to systematically record information on rare earth oxide-containing glass fillers - apart from product information such as lot number.

\section{CONCLUSIONS}

In this study, we developed a fluorescent glass filler which induced a small color change in composite resins. We then used it in a composite resin to enhance the latter's visual inspection capability. The $\mathrm{Eu}_{2} \mathrm{O}_{3}$ containing filler fluoresced clearly and visibly when irradiated with purple or near ultraviolet light. Fluorescence intensity of the prepared composite resin increased with increase of $\mathrm{Eu}_{2} \mathrm{O}_{3}$ content in the glass filler and with filler/resin ratio in the resin. Nevertheless, addition of up to $10 \mathrm{wt} \% \mathrm{Eu}_{2} \mathrm{O}_{3}$ to the glass filler did not change the color of the composite resin. $\mathrm{Tb}_{4} \mathrm{O}_{7}$ - and $\mathrm{Dy}_{2} \mathrm{O}_{3}$-added fillers also showed clear fluorescence. The emissions of $\mathrm{Eu}_{2} \mathrm{O}_{3}, \mathrm{~Tb}_{4} \mathrm{O}_{7}$, and $\mathrm{Dy}_{2} \mathrm{O}_{3}$ were characteristic of these elements, and hence easily identified and assigned in the spectra. Therefore, in the present study, fluorescent glass fillers for composite resins were successfully prepared where color change in composite resin was negligibly small and that the possibility of systematic data recording was also suggested.

\section{ACKNOWLEDGEMENTS}

This study was supported by a Grant-in-aid for Scientific Research ((B) No. 15390581) from the Minis- try of Education, Culture, Sports, Science, and Technology, Japan. A part of this work was also supported by Research on Advanced Medical Technology in Health and Labor Sciences Research Grants from the Ministry of Health, Labor, and Welfare of Japan.

\section{REFERENCES}

1) Bello A, Jarvis RH. A review of esthetic alternatives for the restoration of anterior teeth. J Prosthet Dent 1997; 78: 437-440.

2) van Dijken JWV. Direct resin composite inlays/onlays: An 11-year follow-up. J Dent 2000; 28: 299-306.

3) Arikawa H, Kanie T, Fujii K, Homma T, Takahashi H, Ban S. Optical properties of paint-on resins for shade modification of crown and bridge resins - Light transmittance characteristics. Dent Mater J 2003; 22: 272-279.

4) Soma H, Miyagawa Y, Ogura H. Setting and flexural properties of metal-resin composite using $\mathrm{Ag}-\mathrm{Cu}$ particles as filler and chemical accelerator. Dent Mater J 2003; 22: 543-555.

5) Bayindir YZ, Yildiz M, Bayindir F. The effect of "softstart polymerization" on surface hardness of two packable composites. Dent Mater J 2003; 22: 610-616.

6) Arksornnukit M, Takahashi H, Nishiyama N. Effects of silane coupling agent amount on mechanical properties and hydrolytic durability of composite resin after hot water storage. Dent Mater J 2004; 23: 31-36.

7) Tjandrawinata R, Irie M, Yoshida Y, Suzuki K. Effect of adding spherical silica filler on physico-mechanical properties of resin modified glass-ionomer cement. Dent Mater J 2004; 23: 146-154.

8) Arikawa H, Kanie T, Fujii K, Ban S, Homma T, Takahashi H. Optical and color stabilities of paint-on resins for shade modification of restorative resins. Dent Mater J 2004; 23: 155-160.

9) Matsumoto H, Kitamura S, Araki T. Applications of fluorescence microscopy to studies of dental hard tissue. Front Med Biol Eng 2001;10: 269-284.

10) Fujikawa K, Sugawara A, Kusama K, Nishiyama M, Murai S, Takagi S, Chow LC. Fluorescent labeling analysis and electron probe microanalysis for alveolar ridge augmentation using calcium phosphate cement. Dent Mater J 2002; 21: 296-305.

11) Shigetani $Y$, Okamoto A, Abu-bakr N, Tanabe K, Kondo S, Iwaku M. Caries diagnosis sing a laser fluorescence system - Observation of autofluorescence of dental caries. Dent Mater J 2003; 22: 56-65.

12) Tani K, Watari F, Uo M, Morita M. Discrimination between composite resin and teeth using fluorescence properties. Dent Mater J 2003; 22: 569-580.

13) Tani K, Watari F, Uo M, Morita M. Fluorescent properties of porcelain-restored teeth and their discrimination. Mater Trans 2004; 45: 1010-1014.

14) Tanabe S. Kidorui no Kagaku (Adachi G ed.), Kagaku Dojin, Kyoto, 1999, pp.775-811. 